\title{
New Variant PhD: The changing nature of the doctorate in the UK
}

\author{
Chris Park ${ }^{\star}$ \\ Lancaster University, UK
}

\begin{abstract}
Since the early twentieth century the PhD has been the research degree of choice in the UK, but traditional ideas and practices relating to the degree are now being challenged. This paper sketches out the main drivers of change and explores the main challenges confronting doctoral study within the UK. It explains why there is a need for a wholesale revision of assumptions and expectations about what the $\mathrm{PhD}$ is, and it charts the genesis and evolution of the $\mathrm{PhD}$ in the UK. Key drivers for change include a new emphasis on skills and training, submission rates and quality of supervision, changes in the examination of the thesis, and the introduction of national benchmarking. The paper then explores changes in the $\mathrm{PhD}$ as product and as process, and outlines how and why new forms of doctorate are emerging. It asks, rhetorically, whether the changing nature of the doctorate reflects adaptation to changing circumstances in order to survive.
\end{abstract}

\section{Introduction}

The doctorate is the highest academic degree that universities in the UK can award. The traditional and still the most common doctorate in the UK is the Doctor of Philosophy (PhD or DPhil), a research degree awarded for demonstrating ability to carry out academic research and to produce new knowledge. A typical earned (as opposed to honorary) doctorate in the UK involves three years full-time study, or part-time equivalent, much of it involving research at the leading edge of the discipline. To gain the award, a student is typically required to make a substantial original contribution to knowledge, evidenced through a thesis that is examined by academic peers.

Entry standards into the $\mathrm{PhD}$ are usually defined by prior academic attainment, most usually in the form of at least a second-class honours degree. Research students benefit from the experience of studying at postgraduate level before they embark on a doctorate, and whilst it is rarely a prerequisite, an increasing number have completed a Masters programme which includes a substantial amount of research training and a

^The Graduate School, Lancaster University, Lancaster LA1 4YB. Email: c.park@lancaster.ac.uk ISSN 1360-080X (print)/ISSN 1469-9508 (online)/05/020189-19 
dissertation or thesis. Funding for doctoral research is usually easier to secure if the student can evidence research ability and potential in the form of an appropriate Masters award.

But the traditional $\mathrm{PhD}$ model is now being challenged by a growing diversity of types of doctoral degree, including $\mathrm{PhD}$ by publication, Professional Doctorates, and New Route PhD. Traditional expectations of the $\mathrm{PhD}$ are being challenged by the new context within which research degrees are now situated and evaluated, including a new emphasis on research training, supervision, submission rates and external definition of the quality and standard of awards.

The objective of this paper is to sketch out the main drivers of change and to explore the main challenges confronting doctoral study within the UK. The paper calls for nothing less than a wholesale revision of assumptions and expectations about what the PhD is, or could conceivably be today, given the new and still emerging context within which it is situated and constructed.

\section{Reflection}

In some ways, this process of reflection is already under way. The rhetorical question "what is a $\mathrm{PhD}$ ?" has already been asked, both directly (e.g. Underwood, 1999; Burnard, 2001) and indirectly (e.g. Hockey, 1991). Collinson (1998) has noted how in Britain in recent years the doctorate has been reconceptualised as a training period for future researchers, rather than a piece of work that changes the course of human knowledge. Based on personal experience, Pole (2000) views the PhD student as a blend of technician and scholar, and Trotter (2003) describes her PhD in social work as a mixture of "researching, studying or jumping through hoops".

In recent years the fitness for purpose of the doctoral qualification has been widely questioned in the UK, particularly by students and employers. "For some time this single-purpose qualification has no longer fitted the expectations of students and employers. Increasingly, Government, funding bodies and higher education institutions (HEIs) are questioning the nature of the PhD" (Anon., 2002). The Harris Report (1996) argued that it is not always clear to students and employers what it means to have been awarded a particular postgraduate qualification. The Roberts Report (2002) concluded that institutions are not adapting quickly enough to the changing experiences of existing students, the expectations of potential students or the need to prepare students for careers beyond the academy.

Reflection has also been encouraged by the need to reconcile different perceptions of stakeholder benefit, because the doctoral degree - viewed through different lenses - can mean different things. For the student it can be an "academic passport with international reciprocity" (Noble, 1994), a licence to teach at degree level, and an apprenticeship in "proper" academic research (Armstrong, 1994). For the university, PhD students are "the army of research 'ants", as Mitchell (2002) puts it, which helps to keep the research mission moving forward whilst many academics are overloaded with responsibilities. Having research degree awarding powers is a 
major sign of the status and academic credibility of a university, and those research universities which award doctorates situate themselves at the pinnacle of the ladder of academic qualifications (Stauffer, 1990). Indeed, the European University Association, which has a membership of nearly 700 universities from all European countries, describes a university as having full powers to award doctoral degrees. For the subject or discipline, the research carried out by doctoral students is vitally important, because many doctoral students are the professors of the future, and most doctoral research gives rise to new knowledge, new interpretations and new explanations. In this sense, research students act as stewards of a discipline (Jackson, 2003) with a responsibility to keep it not just alive, but intellectually vibrant. For the nation, the obvious benefits of an active community of scholars engaged in doctoral level research include enhanced creativity and innovation, and the development of intellectual capital and knowledge transfer, which drive the knowledge economy and are engines of the growth of cultural capital.

Debate about the meaning and value of the doctorate is neither new nor confined to the UK. More than two decades ago, Spriestersbach and Henry (1978) noted that, in the USA, "the standards of $\mathrm{PhD}$ education remain unexplained and the appropriateness of existing practices in $\mathrm{PhD}$ education largely undemonstrated." Cude (1987) describes many North American doctoral programmes as inflexible, cumbersome, restrictive and wasteful, and has more recently noted that "as it presently functions in most disciplines, [the doctoral programme] has become a trap for the candidate and a sinkhole for intellectual resources" (Cude, 2001). Beyond North America, the doctoral debate has also surfaced in Australia (Sheely, 1996; Mullins and Kiley, 1998, 2000; Pearson, 1999) and in New Zealand (Sutherland, 1999). In Europe, too, different countries have developed different research training systems leading to doctoral degrees, although Kyvik and Tvede (1998) suggest a trend toward a common international doctorate. Increasing harmonisation of the higher education landscape across Europe, driven by the Bologna Declaration (van der Wende, 2000), is likely to promote further convergence.

\section{Genesis}

The British PhD is a relatively new degree. It has its roots in the birth of universities in medieval Europe, in the thirteenth century where the award of a doctorate was a licence to teach, not a recognition of ability or achievement in research. As Simpson (1983) pointed out, "Masters and Doctors degrees were ... the only qualification conferred and cannot in any sense be regarded as higher degrees. ... The twentieth century research degree had no equivalent in the medieval university".

It was in Germany that the doctorate came to acquire special status as a research degree, and this development owed much to the vision of Humboldt, who founded the University of Berlin in 1810 as the first modern research university (Wyatt, 1998). The award of a doctorate required successful attendance at seminars, submission of an acceptable thesis, and the passing of a comprehensive oral 
examination, and the emphasis was on original and creative research (Goodchild and Miller, 1997). Academic staff were invariably required to hold a $\mathrm{PhD}$ degree, engage in research and publish scholarly material. Beginning in 1815, the academic credibility and vitality of the German universities lured bright and ambitious graduate students from Britain and America, who had no suitable opportunities at home (Simpson, 1983). Many of them, armed with German PhDs, returned home and were employed in colleges and universities, slowly helping to raise the profile of academic research in US universities (Schatte, 1977).

From the 1860s onwards the United States began to import from Germany the notions of research universities and doctoral degrees. Yale was the first American university to adopt the $\mathrm{PhD}$ degree (1861), and other American universities including Harvard, Michigan and Pennsylvania soon followed. The Yale PhD required students to complete specialised courses, enrol for three years, demonstrate reading knowledge of at least one foreign language, pass a comprehensive examination, submit a dissertation [thesis], and pass an oral examination [viva] (Buchanan and Herubel, 1995). Graduate education spread rapidly through North America between 1870 and 1900, and "by the end of the nineteenth century, the PhD had become the sine qua non of American [university] teachers" (Simpson, 1983).

From Germany and the United States the research degree spread to Britain from 1917, and then onwards to most English-speaking countries including Canada and Australia (Schatte, 1977; Simpson, 1983; Nelson, 1993; Noble, 1994). In Britain, higher doctorates (the DSc and DLitt) had been introduced by the Universities of London, Edinburgh, Oxford and Cambridge during the 1870s, but the first lower doctorate (the $\mathrm{PhD}$ ) was not introduced until 1917, initially by Oxford. Simpson (1983) notes how "within three years the $\mathrm{PhD}$ had been established in almost all departments of all British universities and with practically identical regulations."

\section{Drivers of Change}

The traditional $\mathrm{PhD}$, long seen as the premier higher degree in the UK, for many people still remains the research degree of choice. But the context within which it operates is changing, and whilst none of these changes in itself threatens to undermine the $\mathrm{PhD}$, taken together they amount to no less than a sea-change which HEIs are having to adapt to. Failure to adapt quickly and appropriately enough could imperil an institution's ability to continue to support postgraduate research students, particularly in the face of the new HEFCE definition of quality standards for research training programmes (Metcalfe, Quinton and Green, 2002). At risk is continued funding to support higher degree research activities, from funding councils and research councils.

The key drivers of change are a growing emphasis on skills and training, on submission and completion rates, and on quality of supervision, along with changes in the examination of the thesis, and the introduction of benchmarking. 


\section{Skills and Training}

The skills and training agenda at $\mathrm{PhD}$ level is not new. In the mid-1990s the Dearing Report (1996) recommended enhanced provision of skills training and research support, and the Harris Report (1996) located research training logically within academic departments and faculties, where the research-active staff are based. More recently, the Roberts Report (2002) argued that the traditional focus in PhD research on production of the thesis has led to failure to recognise the need to acquire a wide range of skills. Frame and Allen (2002) have called for a more flexible approach to research training within PhD programmes, and the recent HEFCE review of PGR training programmes (Metcalfe, Quinton and Green, 2002) underlines the commitment to training in transferable skills by funders.

Undertaking a $\mathrm{PhD}$ has traditionally been viewed as a form of academic apprenticeship, and training inevitably has a part to play in producing the wellrounded academic practitioner. As the British Psychological Society (no date) put it, "essentially, a $\mathrm{PhD}$ is a training and apprenticeship in research, a period of learning the tricks of the trade, of becoming a professional, and of establishing yourself as a peer among experts." According to the UK Council for Graduate Education (1997) doctorateness involves "mastery of the subject; mastery of analytical breadth (where methods, techniques, contexts and data are concerned) and mastery of depth (the contribution itself, judged to be competent and original and of high quality)." Mullins and Kiley (2000) insist that, in the apprenticeship model, "a PhD is a period during which, amongst other things, a student learns the art and the science of research, the ethics of research, the intellectual rigour required of a researcher, how to frame research questions and to pursue them and mould them, and to complete a piece of original research."

In the UK, "the research element of the doctorate remains the distinctive characteristic and essential cornerstone" of the $\mathrm{PhD}$ (UK Council for Graduate Education, 1996a), although much discussion has focussed on how much research training the PhD should provide (Becher, Henkel and Kogan, 1994; Burgess, 1997), particularly training in research methods (Collinson, 1998) and research skills (Delamont, Atkinson and Parry, 1997; UK Council for Graduate Education, 1996a, 1996b, 1998). Given that, "postgraduate research education is the principal vehicle for training teachers in HE" (Harris Report, 1996) there have also been calls for better training in teaching (UK Council for Graduate Education, 1999).

What is new is the demand from funding bodies and potential employers that training within $\mathrm{PhD}$ programmes should be more structured and better coordinated, that it be broadened to embrace key or transferable skills as well as research skills, be compulsory rather than optional, and be more sensitive to issues of employability that extend beyond simply creating new academics. Although a $\mathrm{PhD}$ is still the main entry qualification for an academic post (Henkel and Kogan, 1993), limited career opportunities within universities mean that the $\mathrm{PhD}$ must also prepare the student for other kinds of employment (Harvey, 2000; UK Council for Graduate Education 1996a, 1998). The evidence suggests that such diversification is occurring 
in a number of European countries as well as in the UK (Huisman, de Weert and Bartelse, 2002).

\section{Submission and Completion Rates}

In the UK, submission rates have not (yet) given rise to the "hidden crisis in HE" that Lovitts and Nelson (2000) claim exists in the United States, where half of the graduate students leave without completing their degrees. Of course, academic cultures and contexts differ between the UK and the USA, but recent years have witnessed growing interest in variations in $\mathrm{PhD}$ submission rates within and between HEIs in the UK, even though comparative studies are constrained by the lack of published data on submission and completion rates. What the North American literature calls "time-to-completion" varies between countries within Europe, by a matter of up to 7 years, although most students spend the equivalent of between 3 and 3.5 years on the research itself and the rest on writing up (McQueen, 1994).

There is an inevitable tension between quality of research and submission and completion rates, because the objective of achieving timely submission might at times compromise the objective of high quality research. Many supervisors feel uncomfortable with the new imperative to meet threshold submission rates, particularly when they are set as high as 70 per cent submission within four years (full-time). It is easy to view thresholds like this as a managerialist approach to academic quality, that puts undue emphasis on performance indicators of "efficiency" that are open to misinterpretation and misrepresentation. These concerns are very real, because funding council and research councils are planning to use submission rates as a proxy for the quality and effectiveness of research training and supervision, despite abundant evidence that submission rates reflect the interplay of multiple factors.

Perhaps inevitably, submission rates are affected by different factors in different countries, and by multiple factors within any given country. Amongst a wealth of North American studies, for example, Pauley, Cunningham and Toth (1999) identified six factors positively related to doctoral degree completion - student financial support, familial support, peer support, faculty support, chairperson support and student motivation. In Australia, Dinham and Scott (1999) discovered that doctorate completion rates can be significantly affected by financial difficulties, family lifestyle problems, cultural difficulties and isolation, and problems dealing with university administration. Empirical research on reasons for non-submission or late submission in the UK has to date been somewhat limited. Rudd (1986) discovered that students drop out for many reasons, including individual characteristics, personal problems and accidents, problems inherent in research projects and poor supervision. Booth and Satchell (1996) showed that doctoral completion rates vary with discipline (rates were highest in sciences), student ability (measured by first degree type), and fee status (rates were higher for full-time 
students, pro-rata), with funding having an insignificant positive impact on completion rate. Wright and Cochrane (2000) confirm the importance of discipline, with science students much more likely than non-science students to complete their theses, on time or even at all.

\section{Quality of Supervision}

One hallmark of the new culture of doctoral research in the UK is a growing emphasis on quality of supervision, which can have significant impacts particularly on the quality of the student experience, time to submission, and likelihood of eventual completion and graduation. This area, traditionally viewed as a secret garden or an activity that takes place behind closed doors between consenting adults, is now expected to be more transparent, more consistent and more appropriate to contemporary notions of what the $\mathrm{PhD}$ is and how it should be undertaken. The traditional practice was to regard successful completion of a $\mathrm{PhD}$ as an apprenticeship that then bestows eligibility to supervise others. Institutional cultures and practices in this area vary (Delamont, Atkinson and Parry, 1998), but the funding councils and the research councils increasingly favour proper selection, induction and training of supervisors.

Effective supervision relies heavily on the nature of the relationship between student and supervisor, not just in terms of academic match and experience but also in terms of style of supervision, evidenced through such qualities as flexibility and sensitivity (Hockey, 1996a). Gurr (2001) stresses the importance of a constructive alignment between supervisory style and student development, orientated around the fostering of "competent autonomy" within the student. One approach to strengthening the supervisor-student relationship is to develop and use a negotiated written contract (Hockey, 1996b), although it is difficult to use structural measures like this to deal effectively with issues such as lack of student motivation.

Critical to effective supervision is the supervisor's understanding both of their role and of how they can best help the student to achieve their full potential. This is informed by a range of factors, including the various intellectual, functional and selfesteem motives of the supervisor (Hockey, 1996c). Supervisors of doctoral students require many of the skills of the workplace manager (Vilkinas, 2002), although the roles are not identical.

Effectiveness also reflects the student experience of the quality and nature of research supervision, judged in the light of their expectations. Although it is not easy to capture experience or expectations in unambiguous ways (Marsh, Rowe and Martin, 2002), it is clear that experience often falls short of expectations, in both personal indirect research-related help and direct research-related help (Haksever and Manisali, 2000). Appropriate training of $\mathrm{PhD}$ supervisors might help to address this shortfall (Pole et al., 1997), but it must be accompanied by efforts to inform student expectations and make them more realistic. 


\section{Examining the Doctorate}

From the student's perspective, one of the most important ingredients of the doctoral experience is the examination process, which determines whether or not the degree is awarded. There are two key dimensions to this critical step - the process (how the work is examined) and the focus (precisely what is examined).

Traditionally in the UK the thesis is examined in an oral examination (the viva voce) by academic peers who hold doctorates themselves, are research-active academic practitioners and can assess expert knowledge. The viva usually involves at least one examiner internal to the institution and one external examiner. The doctoral degree is not graded; a candidate may pass, or may pass after making corrections and revisions, or may be failed (possibly with a recommendation to resubmit for a lesser award).

The examination process varies between universities across the UK. Tinkler and Jackson (2000) found that "although there is a large degree of inter-institutional consistency regarding key criteria for the $\mathrm{PhD}$ award, close inspection of institutional policy suggests that the $\mathrm{PhD}$ examination is in fact conceptualized and operationalized in diverse ways". Jackson and Tinkler (2001) also found no consensus regarding the role of the viva in the $\mathrm{PhD}$ examination process between different universities in the UK, and "inconsistencies and contradictions concerning its purposes, both at the policy and practice levels". Because of the authority and responsibility delegated by the awarding university to the examiners engaged in the viva, and the lack of absolute standards against which to judge each individual thesis and its writer, the doctoral examination can be viewed as a socially constructed encounter rather than a fully objective and impartial process (Park, 2003).

Recent years have witnessed a change in the focus of doctoral examinations, informed by the emerging culture of UK higher education and its emphasis on quality assurance, standards, benchmarks and performance indicators (Morley, Leonard and David, 2002). "Traditionally the function of the $\mathrm{PhD}$ has been to train future academic workers. The research content, not the training of the researcher, has been its main outcome" (Anon., 2002). But this is changing in the UK, albeit slowly, with attention now also being paid to testing of the process, looking for evidence of research training and the development of the autonomous academic researcher but with a broader skills-base for the majority of doctoral graduates whose careers will be outside academia.

In this sense the UK is simply playing catch-up with other countries, such as the USA and Australia. A decade ago the University of New England told its doctoral examiners that "the primary purpose of the candidature is advanced training in research methods. It is therefore important that the skill, competence and ability of the candidate be fairly assessed irrespective of the finality of the research results" (Nelson, 1993). The University of Melbourne (no date) insists that one of the key criteria for defining a successful doctoral thesis is that "it is a careful, rigorous and sustained piece of work demonstrating that a research 'apprenticeship' is complete and the holder is admitted to the community of scholars in the discipline." 
This new way of framing doctoral study - as a combination of training the person and writing the thesis - is captured in the level descriptor published by the Quality Assurance Agency (QAA, 2001), which states that "Doctorates are awarded for the creation and interpretation of knowledge, which extends the forefront of a discipline, usually through original research. Holders of doctorates will be able to conceptualise, design and implement projects for the generation of significant new knowledge and/ or understanding. Holders of doctorates will have the qualities needed for employment requiring the ability to make informed judgements on complex issues in specialist fields, and innovation in tackling and solving problems."

\section{Benchmarking}

Traditionally in the UK there was no national definition of the quality or standard of a doctoral degree, and external examiners carried much of the responsibility for ensuring parity of quality between institutions. From a quality assurance perspective, to protect the academic credibility and reputation of individual institutions, and to make the whole process more transparent, such an informal approach poses some major challenges. Little wonder, therefore, that the Dearing Report (1996) argued the need to provide clarification of the titles, levels and aims of different programmes, and for a framework of postgraduate awards to provide a clear pathway of progression with different levels reflecting different levels of attainment. This gave rise to the Framework for Higher Education Qualifications (FHEQ) (QAA, 2001) which maps out what a student with a doctoral level degree should be capable of, defines the standards expected of a doctoral degree, and provides a national benchmark against which to judge individual $\mathrm{PhD}$ programmes and schemes.

The FHEQ sits alongside other sector-wide vehicles of quality assurance that HEIs will be expected to comply with, in spirit if not in letter, including the QAA (2000) Code of Practice for Postgraduate Research Programmes, and the forthcoming HEFCE framework for postgraduate research training programmes (Metcalfe, Quinton and Green, 2002). Taken together, these instruments represent a major sea-change in the context of doctoral study in the UK, and one to which each individual institution must adapt (Shaw and Green, 2002). The rationale of enhancing quality and improving accountability is broadly welcomed (Stanley and Patrick, 1998), although not all observers are convinced that the end justifies the means. Critics of this new culture bemoan the advent of creeping managerialism, the imposition of external standards and requirements, and the attendant rise in bureaucracy. Thorne and Francis (2001) suggest that the new vehicles fail to recognise some important qualitative distinctions between different types of doctoral programme.

\section{PhD as Product}

It is useful to distinguish between the $\mathrm{PhD}$ as a product, and the $\mathrm{PhD}$ as a process. 
The main tangible product is the thesis that each student must present, which describes a substantial piece of original research and is examined in the viva. Each $\mathrm{HEI}$ has its own regulations that define what $\mathrm{PhD}$ is and spell out expectations over such things as style, format and content. Alternative formats of thesis are permissible in some disciplines, such as the creative arts, where what is examined may take the form of performance and/or a portfolio of creative work accompanied by a narrative thesis that contextualises and evaluates the work.

The traditional notion of the magnus opus - a piece of research that could have a lasting impact on a discipline - has over the last decade or so been replaced by a more pragmatic notion of a manageable piece of work, of a scope and size that a student could reasonably expect to complete within three years. Scale is important in two ways: in terms of the length of time the student works on the research, and the size of the thesis describing that research. Scoping is becoming more important than it was in the past, and is increasingly codified in institutional regulations. A doctoral thesis at York University (no date), for example, is defined as "a piece of work which a capable, well-qualified and diligent student, who is properly supported and supervised, can complete within three years". Mullins and Kiley (2002) remind examiners that they are evaluating a "PhD not a Nobel Prize", so they must keep in mind the timescale of the research, the constraints under which the student had to operate, and the normal disciplinary expectations about quantity and quality of work under scrutiny. Typical word-length can very between disciplines, but between 80,000 and 100,000 words is a typical maximum allowed under university regulations. Few institutions allow theses to be longer than 100,000 words without special prior approval.

Typically, a PhD thesis is expected to embody independent research carried out by the author, and through that to demonstrate that the student has located the research within a discipline or an interdisciplinary context, has shown an ability to carry out independent research as an autonomous practitioner, and has made a substantial contribution to knowledge and advanced understanding. It is generally agreed that a doctorate should involve extending knowledge, but the two most difficult criteria to legislate for, and to benchmark in any meaningful way, are originality and contribution to knowledge.

Originality can be a thorny problem, because it means different things in different disciplines, there is no absolute threshold that can be applied, and constraints of time and funding must also be taken into account. Moreover, originality can be displayed in a number of ways - including reinterpreting an existing theory or data, "applying an existing position, theory or methodology to a new range of data, ... finding new ways of analysing and/or theorising a known body of information, and ... [proposing] a new method and/or theory, and applying it to a new range of data or information." (Sussex, no date).

Many HEIs in the UK have regulations that require a $\mathrm{PhD}$ thesis to contain an original contribution to knowledge or understanding. As Mullins and Kiley (2000) stress, "a PhD thesis ... should be, above all, seen to be a stage in the process of 
developing new knowledge in a particular field". Thus, for example, Cambridge University (no date) expects that "a dissertation for the $\mathrm{PhD}$ must represent 'a significant contribution to learning', for example through the discovery of new knowledge, the connection of previously unrelated facts, the development of a new theory, or the revision of older views, and must take account of previously published work on the subject." This traditional notion of a $\mathrm{PhD}$ almost inevitably privileges the creation of new knowledge over the application, extension, interpretation or questioning of existing knowledge.

\section{PhD as Process}

An emerging theme in doctoral discourse in the UK is the switch from content to competence, driven by a shift in emphasis towards the $\mathrm{PhD}$ experience for the student, and away from simply the outcome (award of the degree) or the product (the thesis). The ultimate aim is to produce the autonomous scholar (Johnson, Lee and Green, 2000), even though a majority of doctoral students end up in nonacademic careers.

In a North American context, Golde and Dore (2001) note the lack of understanding with which many students approach graduate study. They observe that "many students do not understand what doctoral study entails, how the process works, and how to navigate it effectively. There is a mismatch among the purpose of doctoral education, the aspirations of the students, and the realities of their careers within and outside academia" (Golde and Dore, 2001). One response in the UK to this desire to make the process more transparent has been the growth of a cottage industry (e.g. Cryer, 1996; Phillips and Pugh, 2000) in writing guidebooks to help students to better understand what the experience of being a research student involves.

A key component of the student experience of doctoral study is the transition into a new culture and context within higher education, which involves what Haden (1993) describes as "taking the $\mathrm{PhD}$ plunge". Many HEIs run induction programmes designed to help the new doctoral student to adjust to their new status as novice researchers, which involves intellectual solitariness, professional and social isolation, new work organisation requirements, anxiety concerning time and productivity, intellectual life, and supervision (Hockey, 1994). Warrington (1997) and RheddingJones (1997) confirm how personally challenging this transition experience can be.

Published insights of the doctoral student experience come mainly from North America, where Haden (1993) suggests that "to survive in today's graduate school, a student must be technically literate, stay organized, choose suitable living arrangements, keep fit, and maintain close ties with family and friends." The particular challenges faced by minority groups such as latinos (Gonzales et al., 2002), blacks and native Americans (Roach, 2001), and the influence of gender and gendered perspectives (Cao, 2001), can make the process even more problematic for the individual student. 


\section{Diversity of Provision - Emergence of New Forms of Doctorate}

Since it first arrived in the UK in the early twentieth century, the PhD has been the research degree of choice. Whilst its supremacy is not in itself under attack, the emergence of new forms of doctorate within the last two decades has diversified the portfolio of doctoral provision, allowed more niche-marketing, and been a response to changing needs and opportunities. Alongside the traditional $\mathrm{PhD}$, many UK HEIs now offer one or more PhDs by publication (rather than by thesis) (Wilson, 2002), practice-based doctorates (for example in the creative and performing arts), professional doctorates (in a variety of forms and formats), and more recently the New Route PhD.

The emergence of this diversity is a response to multiple drivers, particularly the move from content to competence, although as Hockey (1991) points out, the debate over whether a doctoral degree should be viewed as education or training is neither new nor confined to the UK. In Engineering, for example, the development of competence-based doctorates has been informed by an appreciation of the need to adequately prepare students to become experts in the new industrial engineering and development culture (Owens, 1992).

Of the new variants on the traditional $\mathrm{PhD}$, professional and work-based doctorates have up to now commanded most attention, because the number on offer is growing at a relatively fast rate. Maxwell (2003) traces the evolution from first to second generation professional doctorate, and Bourner, Bowden and Laing (2001) identified 20 distinctive features common to professional doctorates in English universities. Pearson (1996) sees the professional doctorate "as a form of professional education in which students are introduced to the professional practice of research and scholarship, with the supervisor responsible for assisting students to become independent practitioners". Key ingredients in this metamorphosis include reflection and planning by the student (Doncaster and Thorne, 2000), appropriate work experience for and the development of personal capabilities in the student (Doncaster and Lester, 2002), and changing roles and responsibilities for the research supervisor (Evans, 1997).

Professional doctorates take many different forms, which reflect the different needs of the subject areas involved. The Doctorate in Education (DEd or EdD) one of the best developed of the applied or practitioner professional degrees in the USA (Townsend and Wiese, 1991) and Australia (Lockhart and Stablein, 2002) arrived in the UK in the early 1990s and has since grown steadily. This development has not been without controversy, though, because there is little evidence that it benefits educational practice at large (Townsend, 2002), and many research universities have remained reluctant to offer the degree (Osguthorpe and Wong, 1993). More fundamentally, Gregory (1995) has questioned the need to differentiate between the Doctorate in Education and the $\mathrm{PhD}$ degree in Britain, and the misassumption that doctoral study is primarily academic apprenticeship.

Beyond the Doctorate in Education, the Doctorate in Clinical Psychology (DClinPsy) (Hatton, 1994) and the Doctorate in Engineering (DEng) (Owens 
1992) are now well established in the UK, and professional doctorates are starting to appear in other subjects. The Doctorate in Business Administration (DBA) remains new in the UK but is on the increase, in response to dissatisfaction in the business sector with the traditional PhD (Bourner, Ruggeri-Stevens and Bareham, 2000). A number of US institutions have developed Doctorates in Public Administration (DPA) (Sherwood, 1996; Brewer et al., 1999), although the need for a degree distinct from the PhD is contested (Hambrick, 1997) and the DPA has yet to appear in the UK. Another growth area in North America is doctoral nursing education, and whilst some universities offer the Doctorate in Nursing Studies (DNS) (Downs, 1989; Anderson, 2000), the field is still its infancy and a consensus has yet to emerge about degree names or programme definition (Minnick and Halstead, 2002).

The New Route $\mathrm{PhD}$ (which some universities have chosen to call an Integrated $\mathrm{PhD}$ ) was first introduced in the UK at the start of the new millennium, initially as a pilot project in ten universities. The pilot proved successful, and the brand and format has since been made available to other universities across the sector. The aim of this new model is to create a UK doctorate that has more appeal to international students, particularly those who might otherwise find it attractive to study for a $\mathrm{PhD}$ in North America. The New Route PhD is modelled on the North American doctoral model, with taught elements (including research training and advanced disciplinary study) and a smaller thesis, but it is shorter (four years, the first of which is largely dedicated to taking taught courses) and therefore cheaper, but no less rigorous intellectually.

The relatively slow development of new forms of doctorate in the UK has been partly a reaction to mixed messages about the suitability of some of the variants being explored both in and beyond the UK. In Australia, for example, Sheely (1996) notes that "there has been considerable debate about the validity of alternate $\mathrm{PhD}$ programs and suggestions that both the quality of work submitted and the quality of the experience for the candidate would be less than that of a 'real' PhD." In Canada Allen, Smyth and Wahlstrom (2002) outline some historical, political, economic and social reasons for favouring a reinvention of the traditional $\mathrm{PhD}$ to developing professional doctorates. In the UK, Winter, Griffiths and Green (2000) found that many examiners of practice-based doctoral theses in a range of disciplines commented on a lack of intellectual grasp, coherence, engagement with the literature, originality, and generalisability, along with methodological weakness and poor presentation.

Slow development also reflects an element of uncertainty in the UK research degree market, which now has a variety of types of doctoral award on offer, but lacks clarity and coherence (Bourner, Bowden and Laing, 1999). Hoddell, Street and Wildblood (2002) anticipate greater convergence in this marketplace in the future, as the different models of a doctorate embrace the need to meet the requirements of grade descriptors in the Framework for Higher Education Qualifications. 


\section{Conclusions}

This paper outlines a number of important ways in which the doctoral degree in the $\mathrm{UK}$ is changing, in response to factors such as changing market demand, increased external scrutiny of institutions, the arrival of national benchmarking of quality and standards, and the emergence and growth of new forms of doctoral degrees. The $\mathrm{PhD}$, the traditional research degree and still the most common and most popular one, took hold in the UK at the start of the twentieth century, and for much of the time since then it has been the only earned higher research degree on offer.

Changes are afoot within the $\mathrm{PhD}$, both in terms of the product and the process, which are requiring adjustments in the expectations of all of the major stakeholders particularly the students, supervisors and examiners. Drivers of change include a growing emphasis on skills and training, on submission and completion rates, on quality of supervision, and changes in the examination of doctoral research. The sea-change that is already under way looks set to continue for some time yet, as the full impact and consequences of these changes continue to unfold and become apparent. The future of the $\mathrm{PhD}$ degree itself is not at risk, but it will face increasing competition from the many new forms of doctorate that are becoming available.

Two analogues spring to mind that frame this period of rapid change and the need to adapt to changing circumstances in order to survive. Within evolutionary biology, the model of punctuated equilibrium is based on long periods of relative stability punctuated by periodic bursts of rapid change, adjustment and adaptation (Gould and Eldredge, 1977). A second analogue is Kuhn's (1962) model of scientific paradigms, built on the notion of long periods of stability and continuity of paradigm, interrupted and challenged by phases of rapid change and paradigm shift, usually driven by the need to respond to external factors. It is contended that, in the context of the $\mathrm{PhD}$, this adaptation is occurring in two forms or variants - the existing $\mathrm{PhD}$ is changing shape, and new types of doctorate are appearing as intermediate or transitional forms.

\section{References}

Allen, C. M., Smyth, E. M., \& Wahlstrom, M. (2002). Responding to the field and to the academy: Ontario's evolving PhD. Higher Education Research \& Development, 21(2), 203-14.

Anderson, C. (2000). Current strengths and limitations of doctoral education in nursing: Are we prepared for the future? Fournal of Professional Nursing, 16(4), 191-200.

Anon (2002). Profiting from postgraduate talent. Report of a conference held on 11 June 2002, in London. Cambridge: CRAC.

Armstrong, J. A. (1994). Rethinking the PhD. Issues in Science and Technology, Summer 19-22.

Becher, T., Henkel, M., \& Kogan, M. (1994). Graduate education in Britain. London: Jessica Kingsley.

Booth, A. L., \& Satchell, S. E. (1996). British PhD completion rates: Some evidence from the 1980s. Higher Education Review, 28(2), 48-56.

Bourner, T., Bowden, R., \& Laing, S. (1999). A national profile of research degree awards: Innovation, clarity and coherence. Higher Education Quarterly, 53(3), 264-82. 
Bourner, T., Bowden, R., \& Laing, S. (2001). Professional doctorates in England. Studies in Higher Education, 26(1), 65-83.

Bourner, T., Ruggeri-Stevens, G., \& Bareham, J. (2000). The BDA: form and function. Education + Training, 42(9), 481-95.

Brewer, G. A., Facer, R. L., O’Toole, L. J., \& Douglas, J. W. (1999). What's in a name? Comparing DPA and Ph.D. programs. Fournal of Public Affairs Education, 5(4), 309-17.

British Psychological Society (no date). So you want to do a PhD? Guidelines for prospective psychology research students. Retrieved from http://www.ex.ac.uk/bps/phdguide.htm\#what.

Buchanan, A. L., \& Herubel, J. V. M. (1995). The Doctor of Philosophy degree: A selective, annotated bibliography. Westport, CT/London: Greenwood Press.

Burgess, R. G. (1997). The changing context of postgraduate education in the United Kingdom (pp.3-17). In R. G. Burgess (Ed.), Beyond the first degree: Graduate education, lifelong learning and careers. Buckingham: SRHE and Open University Press.

Burnard, P. (2001). What is a PhD? Nurse Education Today, 21(3), 159-60.

Cambridge University (no date). Graduate Studies Prospectus 2004-05. Retrieved from http:// www.admin.cam.ac.uk/univ/gsprospectus/subjects/intro3.html.

Cao, W. (2001). How male and female doctoral students experience their doctoral programs similarly and differently. Ohio: Educational Resources Information Center (ERIC) ED453725. p 31.

Collinson, J. A. (1998). Professionally trained researchers? Expectations of competence in social science doctoral research training. Higher Education Review, 31(1), 59-67.

Cryer, P. (1996). The research student's guide to success. Buckingham: Open University Press.

Cude, W. (1987). The Ph.D. trap. Nova Scotia: Educational Resources Information Center (ERIC) ED31183. p 136.

Dearing Report (1996). Higher education in the learning society. London: National Committee of Inquiry into Higher Education.

Delamont, S., Atkinson, P., \& Parry, O. (1997). Critical mass and doctoral research: Reflections on the Harris report. Studies in Higher Education, 22(3), 319-31.

Delamont, S., Atkinson, P., \& Parry, O. (1998). Supervising the PhD: A guide to success. London: Society for Research into Higher Education. p 209.

Dinham, S., \& Scott, C. (1999). The doctorate: talking about the degree. New South Wales: Educational Resources Information Center (ERIC) ED435305. p 119.

Doncaster, K., \& Lester, S. (2002). Capability and its development: experiences from a workbased doctorate. Studies in Higher Education, 27(1), 91-101.

Doncaster, K., \& Thorne, L. (2000). Reflection and planning: essential elements of professional doctorates. Reflective Practice, 1(3), 391-99.

Downs, F. S. (1989). Differences between the professional doctorate and the academic/research doctorate. Fournal of Professional Nursing, 5(5), 261-265.

Evans, T. (1997). Flexible doctoral research: Emerging issues in professional doctorate programs. Studies in Continuing Education, 19(2), 174-82.

Frame, L. A., \& Allen, L. (2002). A flexible approach to $\mathrm{PhD}$ research training. Quality Assurance in Education, 10(2), 98-103.

Golde, C. M., \& Dore, T. M. (2001). At cross purposes: What the experiences of today's doctoral students reveal about doctoral education. Madison: Wisconsin University, Madison: Educational Resources Information Center (ERIC). p 63. Retrieved from http://www.phd-survey.org.

Gonzalez, K. P., Marin, P., Figueroa, M. A., Moreno, J. F., \& Navia, C. N. (2002). Inside doctoral education in America: Voices of Lainas/os in pursuit of the PhD. Fournal of College Student Development, 43(4), 540-57.

Goodchild, L., \& Miller, M. M. (1997). The American doctorate and dissertation: Six developmental stages. New Directions for Higher Education, 25(3), 17-32.

Gould, S. J., \& Eldredge, N. (1977). Punctuated equilibria: The tempo and mode of evolution reconsidered. Paleobiology, 3, 115-51. 
Gregory, M. (1995). Implications of the introduction of the Doctor of Education degree in British universities: Can the EdD reach parts the PhD cannot? Vocational Aspects of Education, 47(2), $17-188$.

Gurr, G. M. (2001). Negotiating the "rackety bridge" - a dynamic model for aligning supervisory style with research student development. Higher Education Research E Development, 20(1), 81-92.

Haden, F. (1993). Taking the Ph.D. plunge. Executive Educator, 15(4), 32-34.

Haksever, A. M., \& Manisali, E. (2000). Assessing supervision requirements of $\mathrm{PhD}$ students: The case of construction management and engineering in the UK. European fournal of Engineering Education, 25(1), 19-32.

Hambrick, R. (1997). The identity, purpose and future of doctoral education. fournal of Public Administration Education, 3(2), 133-48.

Harris Report (1996). Review of postgraduate education. Bristol: Higher Educational Funding Council for England.

Harvey, A. (2000). Saying when: A recent PhD's perspective on alternative careers. ADE Bulletin, 124 (winter), 40-42.

Hatton, C. (1994). To PhD or not to PhD? The Psy-PAG survey. The Psychologist, 7(5), 212-15.

Henkel, M., \& Kogan, M. (1993). Research training and graduate education: The British macro structure (pp.71-114). In B. R. Clark (Ed.), The research foundations of graduate education: Germany, Britain, France, United States, Fapan. Berkeley: University of California Press.

Hockey, J. (1991). The social science PhD: A literature review. Studies in Higher Education, 16(3), 319-32.

Hockey, J. (1994). New territory: Problems of adjusting to the first year of a social science $\mathrm{PhD}$. Studies in Higher Education, 19(2), 177-90.

Hockey, J. (1996a). Strategies and tactics in the supervision of UL Social Science PhD students. International Fournal of Qualitative Studies in Education, 9(4), 481-500.

Hockey, J. (1996b). A contractual solution to problems in the supervision of $\mathrm{PhD}$ degrees in the UK. Studies in Higher Education, 21(3), 359-71.

Hockey, J. (1996c). Motives and meaning amongst $\mathrm{PhD}$ supervisors in the social sciences. British Fournal of Sociology of Education, 17(4), 489-506.

Hoddell, S., Street, D., \& Wildblood, H. (2002). Doctorates - converging or diverging patterns of provision? Quality Assurance in Education, 10(2), 61-70.

Huisman, J., de Weert, E., \& Bartelse, J. (2002). Academic careers from a European perspective: The declining desirability of the faculty position. Fournal of Higher Education, 73(1), 141-60.

Jackson, A. (2003). Carnegie Initiative on the Doctorate. Notices of the AMS, 50(5), 566-8.

Jackson, C., \& Tinkler, P. (2001). Back to basics: a consideration of the purposes of the PhD viva. Assessment E Evaluation in Higher Education, 26(4), 355-66.

Johnson, L., Lee, A., \& Green, B. (2000). The PhD and the autonomous self: Gender, rationality and postgraduate pedagogy. Studies in Higher Education, 25(2), 135-47.

Kuhn, T. (1962). The structure of scientific revolutions. Chicago: University of Chicago Press.

Kyvik, S., \& Tvede, O. (1998). The doctorate in the Nordic countries. Comparative Education, 34(1), 9-25.

Lockhart, J., \& Stablein, R. (2002). Spanning the academy-practice divide with doctoral education in business. Higher Education Research E Development, 21(2), 191-202.

Lovitts, B. E., \& Nelson, C. (2000). The hidden crisis in graduate education: Attrition from Ph.D. programs. Academe, 86(6), 44-50.

Marsh, H. W., Rowe, K. J., \& Martin, A. (2002). PhD students' evaluations of research supervision: Issues, complexities and challenges in a nationwide Australian experiment in benchmarking universities. Fournal of Higher Education, 73(3), 313-48.

Maxwell, T. (2003). From first and second generation professional doctorate. Studies in Higher Education, 28(3), 279-91. 
McQueen, D. H. (1994). How long does it take to earn a doctorate? An international comparison. European fournal of Engineering Education, 19(2), 215-25.

Metcalfe, J., Thomson, Q., \& Green, H. (2002). Improving standards in postgraduate research degree programmes. Bristol: Higher Education Funding Councils for England, Scotland and Wales.

Minnick, A. F., \& Halstead, L. A. (2002). A data-based agenda for doctoral nursing education reform. Nursing Outlook, 50(1), 24-9.

Mitchell, N. (2002). Surviving the $P h D$. All in the mind (radio programme). Australian Broadcasting Corporation. Transcript retrieved from http://www.abc.net.au/rn/science/ $\mathrm{mind} / \mathrm{s} 668358 . \mathrm{htm}$.

Morley, L., Leonard, D., \& David, M. (2002). Variations in vivas: Quality and equality in British $\mathrm{PhD}$ assessments. Studies in Higher Education, 27(3), 263-73.

Mullins, G., \& Kiley, M. (1998). Quality in postgraduate research: The changing agenda. In M. Kiley, \& G. Mullins (Eds.), Quality in Postgraduate Research: Managing the New Agenda. Adelaide: ACUE, The University of Adelaide.

Mullins, G., \& Kiley, M. (2000). Editorial - tying off the few knots. In M. Kiley, \& G. Mullins (Eds.), Quality in postgraduate research: Making ends meet. Advisory Centre for University Education, The University of Adelaide.

Mullins, G., \& Kiley, M. (2002). "It's a PhD, not a Nobel Prize": How experienced examiners assess research theses. Studies in Higher Education, 27(4), 369-86.

Nelson, H. (1993). A doctor in every house? The PhD then, now and soon. Occasional Paper GS93/3, The Australian National University Graduate School. Retrieved from http://www.anu.edu.au/ graduate/pubs/occasional_papers/GS93_3.pdf.

Noble, K. A. (1994). Changing doctoral degrees: An international perspective. Buckingham: SRHE and Open University Press. p 120.

Osguthorpe, R. T., \& Wong, M. J. (1993). The Ph.D. versus the Ed.D.: Time for a decision. Innovative Higher Education, 18(1), 47-63.

Owens, T. J. (1992). The Engineering PhD - competent for what? Aspects of Educational and Training Technology Series, 25, 287-8.

Park, C. (2003). Levelling the playing field: Towards best practice in the doctoral viva. Higher Education Review, 36(1), 47-67.

Pauley, R., Cunningham, M., \& Toth, P. (1999). Doctoral student attrition and retention: A study of a non-traditional Ed.D. program. Fournal of College Student Retention, 1(3), 225-38.

Pearson, M. (1996). Professionalising Ph.D. education to enhance the quality of the student experience. Higher Education, 32(3), 303-20.

Pearson, M. (1999). The changing environment for doctoral education in Australia: Implications for quality management, improvement and innovation. Higher Education Research $\mathcal{E}$ Development, 18(3), 269-87.

Phillips, E. M., \& Pugh, D. S. (2000). How to get a PhD: A handbook for research students and their supervisors. Third edition. Buckingham: Open University Press, p. 235.

Pole, C. (2000). Technicians and scholars in pursuit of the PhD: Some reflections on doctoral study. Research Papers in Education, 15(1), 95-111.

Pole, C. J., et al. (1997). Supervision of doctoral students in the natural sciences: Expectations and experiences. Assessment E Evaluation in Higher Education, 22(1), 49-63.

Quality Assurance Agency (2000). Code of practice for the assurance of academic quality and standards in higher education: Postgraduate research programmes. Gloucester: The Quality Assurance Agency for Higher Education.

Quality Assurance Agency (2001). The framework for higher education qualifications in England, Wales and Northern Ireland. Gloucester: The Quality Assurance Agency for Higher Education.

Rhedding-Jones, J. (1997). The writing on the wall: Doing a feminist post-structural doctorate. Gender and Education, 9(2), 193-206. 
Roach, R. (2001). A model project. Black Issues in Higher Education, 18(20), 26-8.

Roberts Report (2002). Set for success: The supply of people with science, engineering and technology skills. London: UK Government Department of Trade and Industry and Department of Education and Skills.

Rudd, E. (1986). The drop-outs and the dilatory on the road to the doctorate. Higher Education in Europe, 11(4), 31-6.

Schatte, C. E. (1977). The persisting European heritage of the American Ph.D. Improving College and University Teaching, 25(2), 75-8, 81.

Shaw, M., \& Green, D. H. (2002). Benchmarking the PhD: A tentative beginning. Quality Assurance in Education, 10(2), 116-24.

Sheely, S. (1996). A degree by any other name: An historical reflection on traditional and nontraditional $\mathrm{PhD}$ programs. Different Approaches: Theory and Practice in Higher Education. Proceedings of the HERDSA Conference 1996. Perth, Western Australia, 8-12 July. Retrieved from http://www.herdsa.org.au/confs/1996/sheely2.html.

Sherwood, F. P. (1996). Revisiting the premise of a DPA program after 25 years: sharp differences with the PhD. Fournal of Public Administration Education, 2(2), 107-15.

Simpson, R. (1983). How the PhD came to Britain: A century of struggle for postgraduate education. Guildford: Society for Research into Higher Education. p 204.

Spriestersbach, D., \& Henry, L. (1978). The PhD dissertation: Servant or master. Improving College and University Teaching, 26(1), 52-5.

Stanley, E. C., \& Patrick, W. J. (1998). Quality assurance in American and British higher education: A comparison. New Directions for Institutional Research, 25(3), 39-56.

Stauffer, T. M. (1990). A university model for the 1990s. New Directions for Higher Education, $18(2), 19-24$.

Sussex, R. (no date). A tough test of character. The Orion Educational Society, Queensland, Australia. Retrieved from http://www.orioneducation.com/phdatoughtest.asp.

Sutherland, K. A. (1999). Does teaching matter? Reconceptualising teaching, scholarship, and the PhD programme in New Zealand university English departments. Unpublished PhD thesis. Palmerston North: Massey University.

Thorne, L. E., \& Francis, J. C. (2001). PhD and Professional Doctorate experience: the problematics of the National Framework. Higher Education Review, 33(3), 13-29.

Tinkler, P., \& Jackson, C. (2000). Examining the doctorate: institutional policy and the Ph.D. examination process in Britain. Studies in Higher Education, 25(2), 167-80.

Townsend, B. K. (2002). Rethinking the Ed.D., or what's in a name? Missouri: Educational Resources Information Center (ERIC) ED471507. p 47.

Townsend, B. K., \& Wiese, M. D. (1991). The higher education doctorate as a passport to higher education administration. New Directions for Higher Education, 19(4), 5-13.

Trotter, J. (2003). Researching, studying or jumping through hoops? Reflections on a PhD. Social Work Education, 22(1), 59-70.

UK Council for Graduate Education (1996a). Quality and standards of postgraduate research degrees. Coventry: UKCGE.

UK Council for Graduate Education (1996b). The award of the degree of PhD on the basis of published work in the UK. Coventry: UKCGE.

UK Council for Graduate Education (1997). Practice-based doctorates in the creative and performing arts and design. Coventry: UKCGE.

UK Council for Graduate Education (1998). The status of published work in submissions for doctoral degrees in European universities. Coventry: UKCGE.

UK Council for Graduate Education (1999). Preparing postgraduates to teach in higher education. Coventry: UKCGE.

Underwood, S. (1999). What is a PhD? Towards a discussion paper. Lancaster, England: Lancaster University Higher Education Development Centre, p 13. 
University of Melbourne (no date). PhD Handbook. Retrieved from http://www.gradstudies. unimelb.edu.au/pgstudy/phd/handbk/hdbk_c.html.

van der Wende, M. C. (2000). The Bologna Declaration: enhancing the transparency and competitiveness of European Higher Education. Higher Education in Europe, 25(3), 305-10.

Vilkinas, T. (2002). The PhD process: The supervisor as manager. Education+Training, 44(3), 129-37.

Warrington, M. (1997). Reflections in a recently completed PhD. Fournal of Geography in Higher Education, 21(3), 401-10.

Wilson, K. (2002). Quality assurance issues for a $\mathrm{PhD}$ by published work: A case study. Quality Assurance in Education, 10(2), 71-8.

Winter, R., Griffiths, M., \& Green, K. (2000). The "academic" qualities of practice: What are the criteria for a practice-based $\mathrm{PhD}$ ? Studies in Higher Education, 25(1), 25-37.

Wright, J., \& Cochrane, R. (2000). Factors influencing successful submission of PhD theses. Studies in Higher Education, 25(2), 181-95.

Wyatt, J. (1998). "The lengthening shadow of one man": The public intellectual and the founding of universities. Higher Education Review, 30(2), 29-49.

York University (no date). The degrees of MPhil and PhD. Retrieved from http://www.york.ac.uk/ admin/gso/guidance.htm\#section 1 . 